$\xi=$ 잘

\title{
Use of online sources of information for dental practice among private dental practitioners in Bangalore - a cross sectional survey
}

\author{
Mayur Nath T. Reddy, Hemalatha * \\ Vydehi institute of Dental Science and research centre, Dept of public health dentistry, \\ \#82 EPIP AREA, Nellurahalli, whitefield, Bangalore 560066 \\ *Corresponding author E-mail: Hema.katarii@gmail.com
}

\begin{abstract}
Introduction: The Internet seems to provide a new opportunity to overcome problems of access and provide clinically appropriate information to practitioners. However, while use of the Internet for clinical information has grown substantially in recent years. Access to the Internet has been improving rapidly for all professional groups. Dental professionals in clinical practice have been increasing opportunities to obtain information for clinical decision-making from a variety of resources, including a growing availability through online technology.

Objectives:

1) To assess the frequency of utilizing online sources of information for practical guidance.

2) To assess the influence of online sources of information on practical guidance.

Materials and Methods: A Cross-sectional survey was carried out among 386 private dental practitioners in Bangalore city. A selfadministered, structured questionnaire containing 16 items was used (including demographic details). Cronbach's $\alpha$ was found to be 0.87 for each item. Statistical analysis was done using chi-square test.

Results: $81.6 \%(\mathrm{n}=315)$ of private dental practitioners use the Internet as their source of information for clinical practice. Only $18.4 \%$ $(n=71)$ do not use, the main reason for not using internet is lack of time and it is too complicated to use. $44.8 \%(n=173)$ rated on online source as most influential and $45.6 \%(\mathrm{n}=176)$ frequently using online source for guidance. Information was primarily sought on patient education, oral disease, updates on common disease, and diagnosis. Medline was the most frequently accessed source.

Conclusion: A relatively large proportion of dental practitioners uses information from online sources for practical guidance. The Internet could be a valuable medium for the information, provided, that its use is accompanied by training in the identification, use, and application.
\end{abstract}

Keywords: Practical Guidance; Dental Practitioners; Internet Usage

\section{Introduction}

Information technology is recognized as a useful tool for improving patient safety and quality of care. The Internet has the potential to improve information dissemination and change the way health care is delivered. Social networks may represent a new frontier for health care. By means of social networks, physicians can share medical information with the public, with the potential of a positive impact on health choices and behaviors. On the other hand, conflicts of interest and potential violation of patients' privacy are a matter of concern with the use of this technology. In this respect, the American Medical Association recently issued a policy statement on professionalism in the use of social media by physicians, addressing the need monitoring their own presence on the Internet, adopting privacy measures, and maintaining appropriate boundaries in the online relationship with patients. (Romano M et al 2012, P.1)

The Internet is considered to be a significant source of health information for the general public. It allows increased access to medical and dental information and can be used for patient selfeducation, enabling patients to confirm the information given by their practitioner and to gather additional information (Riodain RN\& Mccreary C 2009, P.583).

The Internet seems to provide a new opportunity to overcome problems of access and provide clinically appropriate information to practitioners. However, while use of Internet for clinical information has grown substantially in recent years. Access to the Internet has been improving rapidly for all professional groups. (Cullen JR 2002, P.370).

Health practitioners need information management skills to cope with the growing volume of medical knowledge. The ability to quickly access, track, coordinate, critique, and store information is essential to informed daily decision making related to patient care, education, and research (Gravois LS 1995, P.446).

Physicians and dentists have diverse information needs when making informed diagnoses and treatment decisions. While medical knowledge continues to grow at a steady pace, clinicians are spending less time with patients, leading to lower patient satisfaction. As a result, identifying information clinicians need at the point of care and accurately and efficiently providing it have become issues of critical importance (Song M et al 2010, P.1).

Translating research findings into everyday practice can be a long process. Dental professionals in clinical practice have increasing 
opportunities to obtain information for clinical decision-making from a variety of resources, including a growing availability through online technology. An increasing majority of practicing dentists today not only have ready access to computers in their offices, but these computers are connected to the Internet (Funkhouser E et al 2014, P.71).

To practice a high quality medicine, physicians have to constantly update their knowledge and find the information they need to integrate the best evidence in their clinical decision. Internet seems to be a relevant tool for information regarding patients care. It is hoped it could help doctors by providing them with the helpful information's they see a patient. Physicians can use the internet to solve clinical problems, to support decision making and to overcome memory limits. The use of online retrieval information systems can help physicians to better answer their clinical questions (Kendra L et al 2006, P.39).

Analysis of the use of information sources by family physicians is important for both practical and theoretical reasons. First, family medicine is a young academic discipline with a growing scientific output. Due to the interdisciplinary nature of this field, effective use of information sources can be a complex challenge, particularly because bibliographic education is not yet common (Anita $\mathrm{AH}$ et al 1995, P.85).

DENTISTS, as health professionals, need access to information. The increase in the rate and volume of information published in dentistry, however, makes it difficult for them to keep up with new procedures and techniques (Strother EA et al 1986, P.227) Dentists are faced daily with challenges of making treatment decisions regarding their patients. As health care providers, it is important that dentists offer the best possible care for their patients. One method that facilitates the decision-making process is a systematic approach that begins with identifying a question around an area of uncertainty regarding a patient treatment, locating the evidence that answers the question, assessing the evidence's validity and relevance, making the decision based on the best available evidence, and finally evaluating the outcomes (Reem N et al 2006, P.1251)

The Internet provides continuing medical education professionals with the ability to offer an extensive array of on-line learning opportunities that have tremendous potential to improve physician knowledge, performance, and clinical effectiveness (Schoen JM et al 2011, P.246) Clinicians are encouraged to regularly update their knowledge and skills, and maintain the standards of clinical excellence required for the optimal care of patients through CME that is aimed at improving performance and optimizing the outcomes of practice (Ryan G et al 2009, P.251)There is a wealth of informational resources available online for clinical decision making in dental practice and continuing dental education (CDE); however, the extent that online technology is utilized in clinical decision making in dentistry or the need for it is not well documented (Funkhouser E et al 2014, P.71).

AIM: To estimate the proportion of dental practitioners who use online sources of information for practical guidance

\section{Objectives}

1) To assess the frequency of utilizing online sources of information for practical guidance.

2) To assess the influence of online sources of information on practical guidance.

\section{Methodology}

A cross-sectional questionnaire survey was conducted in Bangalore city among 386 private dental practitioners who were registered with IDA, Bangalore branch. A self-administered, structured questionnaire containing 16 items was used (including demographic details).

\section{Organization and administration workout}

1) Ethical clearance: The study proposal was approved by institutional review board of Vydehi Institute of Dental Sciences and Research Centre, Bangalore.

2) Informed consent: The purpose and details of the study was explained to the participants and a written consent was then obtained from them.

Inclusion criteria:

- Private dental practitioners in Bangalore city.

- All the Private dental practitioners who had signed the informed consent

Exclusion criteria:

- Private dental practitioners who were not willing to participate in the study.

- Participants who did not sign the consent

Sample size

A total sample size of 386 were included in the study by simple random sampling of all the private dental practitioners in Bangalore city, after meeting the inclusion and exclusion criteria,

Sample size calculation:

Sample Size $=\left\{Z^{2 *}(\mathrm{p}) *(\mathrm{q})\right\} / \Delta^{2}$

Where $\mathrm{Z}=\mathrm{Z}$ value for the confidence level chosen $=1.96$ (for 95\% confidence level - from std normal distribution)

$\mathrm{p}=50 \%=0.50$ (percentage of samples who are utilizing online information)

$\mathrm{q}=1-\mathrm{p}=50 \%=0.50$ (percentage of samples who are not utilizing online information)

\section{$\Delta=$ Margin of error which is acceptable $=0.5($ or $5 \%)$}

Note: $\mathrm{p} \& \mathrm{q}$ are given equal probabilities as no prior information is available.

Therefore, $\mathrm{SS}=\left[(1.96)^{2 *}(0.50) *(0.50)\right] /(0.5)^{2}$

$\mathrm{SS}=386$

Duration of the study

The study was conducted over a period of two months i.e. during September and October 2015.

Pilot study

A pilot study was done among 50 private dental practitioners to check the feasibility and to validate the questionnaire. Face validity of the questionnaire was checked by asking experts to scrutinize the questions, while content validity was checked by ensuring that the questions covered all the areas of knowledge mapped out by initial objective. The reliability of the questionnaire was assessed by using Cronbach's $\alpha$ and it was found to be 0.87

The study design

A cross sectional survey was carried out among private dental practitioners in Bangalore city.

Questionnaire design

A close ended self-structured questionnaire, written in English was used for data collection. Questionnaire consisted of 16 items which includes demographics (questions on name, age, gender, educational qualification, Years of experience, Academician/ Clinician). and questions such as usage of internet, use of information obtained from the internet, sites accessed on the internet and influence of internet on dental practice.

Method of data collection

A self-structured 16 item questionnaire, written in English was used for data collection. The study participants were given the questionnaire in their clinics by a single investigator. The duly filled questionnaire was collected. It was later checked by the 
investigator in case any of the questions were left unanswered. After assessing these questions, findings and observations were tabulated. These tables were analysed and studied.

Statistical analysis

The data was analyzed using SPSS version 16 (SPSS Inc. Chicago, Illinois). Descriptive and inferential statistical analysis has been carried out in the present study. $p$ value $\leq 0.05$ was considered to be statistically significant. Statistical analysis was done using chi square test and Microsoft Excel have been used to generate graphs, tables etc.

\section{Results}

The present study was conducted to estimate the proportion of dental practitioners who use online sources of information for clinical guidance.

Among 386 private dental practitioners who participated in this study, 149 (38.6\%) were between the age group of 25-35 years, $173(44.8 \%)$ between $36-45,64(16.6 \%)$ were > 46 years (Figure 1). Among the participants $209(54.1 \%)$ were males and 177 (45.9\%) were females (Figure 2). Of the respondents, $199(51.6 \%)$ were BDS and 187 (48.4\%) were MDS (Figure 3). Majority of the study participants were clinician $289(75 \%)$ and $97(25 \%)$ were both clinician and academician (Figure 4). 191 (49.5\%) participants had experience of one month to 5 years, $112(29 \%)$ had experience of 6 years to 10 years, $44(11.4 \%)$ had experience of 11-15 years, $23(6 \%)$ had experience of 16-20 years, and $16(4 \%)$ had experience of $>20$ years (Figure 5).

For the question, use of internet, almost all the respondents $(97.7 \%)$ were using internet while $2.3 \%$ were not using internet. $81.6 \%$ of respondents used the online source for clinical practice while $18.4 \%$ reported they did not use online source for clinical information, with various obstacles, most frequently reported obstacles were lack of time $29(7.5 \%)$, too complicated to use $29(7.5 \%)$ followed by $13(2.8 \%)$ too much of information to scan. $27(7 \%)$ of dentist rated their internet skill high, $176(45.6 \%)$ as moderate, $106(27.5 \%)$ as low and $8(2.1 \%)$ as none Table 1 . Majority of dental practioners 114 (29.5\%) had experience of 3 years, 93(24.1\%) with 2 years' experience and $25(6.5 \%)$ with 1year experience followed by $85(22 \%)$ who reported with > 3years. $176(45.6 \%)$ of private practioners used internet occasionally. 99 $(25.6 \%)$ rarely and $27(7 \%)$ frequently. Information about oral/ dental diseases was the leading category of information searched on the Internet 77 (19.9\%) followed by usage of latest technology in to dental practice $73(18.9 \%)$ and $66(17 \%)$ for patient education and management and small number $41(10.6 \%)$ to drug information.

The responders described what kind of information they looked for on the internet this ranged from Information on oral disease/ diagnosis $132(33.2 \%)$, to change or conform treatment plan 83 $(22.8 \%)$ and to change or confirm diagnosis $102(26.2 \%)$. Dentist were asked how they assessed the reliability and validity of medical / dental information on the internet. A relatively large number indicated that they look at the source cited $88(22.8 \%)$ followed by information in repeated journals and $74(19.2 \%)$ by conforming from another source and $72(18.7 \%)$ by research method used. Responders used a range of search on the internet, Medline journals $114(29.5 \%)$ was the most popular search followed by journals 90(23.3\%) physician websites $55(14.2 \%)$ and travel medicine sites $31(8.0 \%)$. Responders described a wide range of strategies for retrieving information PubMed 136 (42.9\%) and Medline 107 $(27.7 \%)$ were used by the majority, followed by $41(12.9 \%)$ of Wiley. Out of 386 dentists 188 (48.7\%) said they doesn't maintain electronic health records while 129 (33.4\%) maintained electronic health records. 222 dentists believed that information in online journals is more reliable than the information published on webpages. 104(26.9\%) got the Continuing Dental Education (CDE) credit points from special conference. 100 (25.9\%) from online CDE services $81 \%$ (21.0\%) from state / local / national dental conference. Highest proportion of practitioners $173(44.8 \%)$ indicated that internet is most influential in dental practice. The information that they were finding on or via the internet was used by interviewers in a number of ways $170(44 \%)$ changed their way of practice. information on internet did not influence 124 (3.1\%) of dentist and $23(6.0 \%)$ reported that they did not get the information searched for. Statistical significance was observed when the overall response was tested for association with age in relation to use of internet (p- 0.002), use of information obtained from internet, years of using internet into dental practice, websites accessed in the internet (p- 0.00) scientific data base used for information (p- 0.001), influence of internet on dental practice ( $p$ 0.000 ) Table 2. Association with gender had significance in use of information obtained from internet, CDE credit points ( $\mathrm{p}-0.004)$, information searched on the internet (p-0.001), Table 3. Association with qualification had significance in years of using internet into dental practice, information searched on the internet, use of information into daily practice, to assess the reliability and validity of information on internet, websites accessed on the internet ( $\mathrm{p}$ $0.000)$, and scientific data base used for information ( $\mathrm{p}-0.001)$ Table 4. Association with experience had significance in use of internet, use of online source, influence of internet on dental practice (p-0.000), years of using internet into dental practice, website accessed on internet, information from online journals are more reliable than webpages (p-0.001), Table 5. Association with Academician/ clinician/both is significant with rating of internet skill, Websites accessed on the internet, CDE points obtained ( $p-0.001$ ), years of using internet into dental practice, information searched on the internet use of information obtained from internet ( $\mathrm{p}-0.000)$ Table 6.

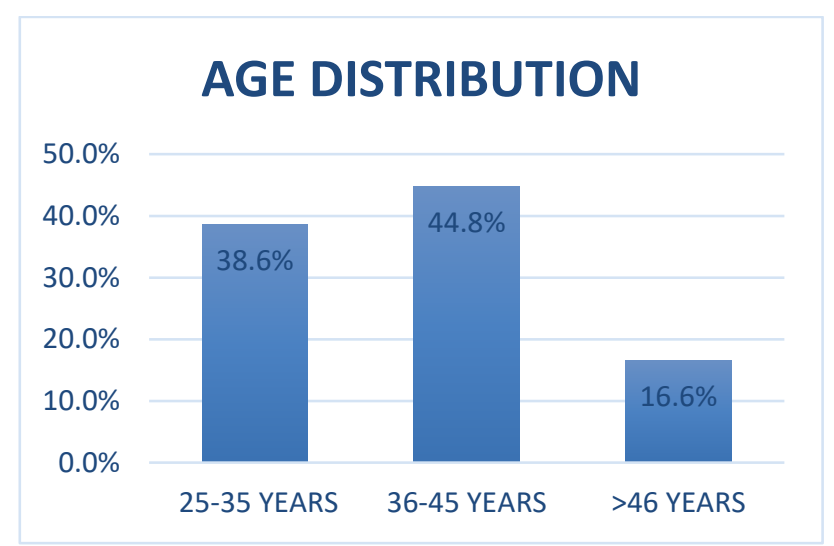

Fig. 1: Distribution of Study Subjects Based on Age. 


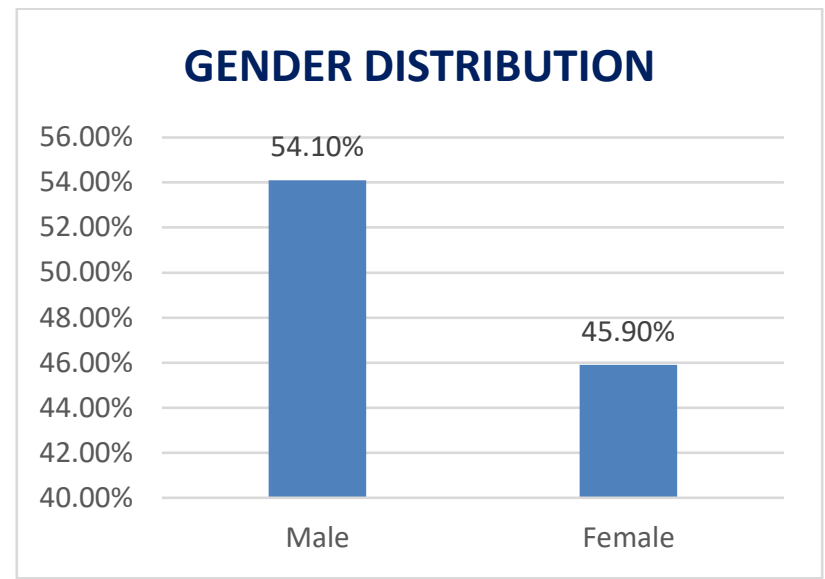

Fig. 2: Distribution of Study Subjects Based on Gender.

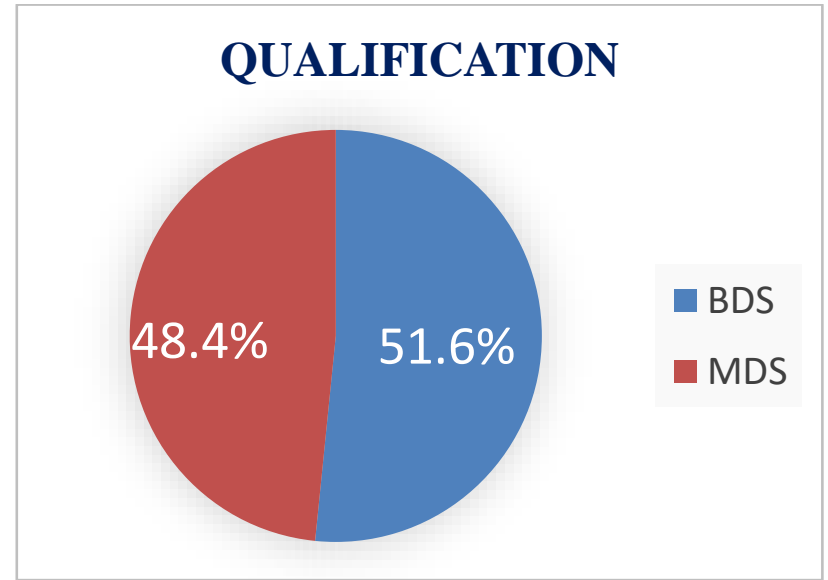

Fig. 3: Distribution of Study Subjects Based on Qualification

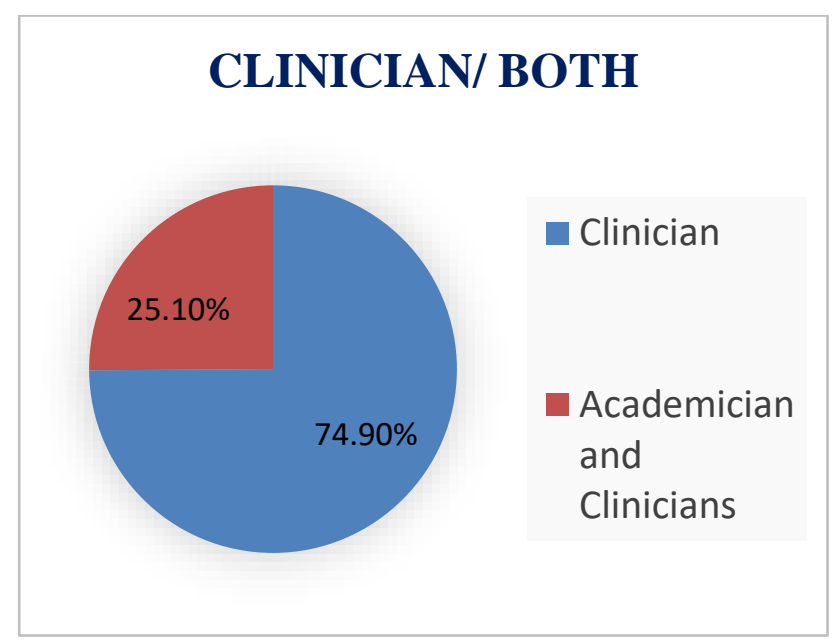

Fig. 4: Distribution of Study Subjects Based on Academician and clinicians 


\section{YEARS OF EXPERIENCE}

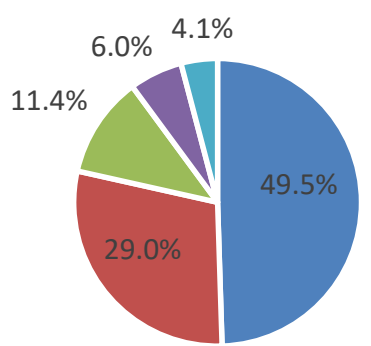

- 1M- 5 Yrs - 6Yrs- 10 Yrs - 11Yrs-15 Yrs

- 16 Yrs-20 Yrs " >20 Yrs

Fig. 5: Distribution of Study Subjects Based on Years of Experience.

Table 1: Response to the Questionnaires

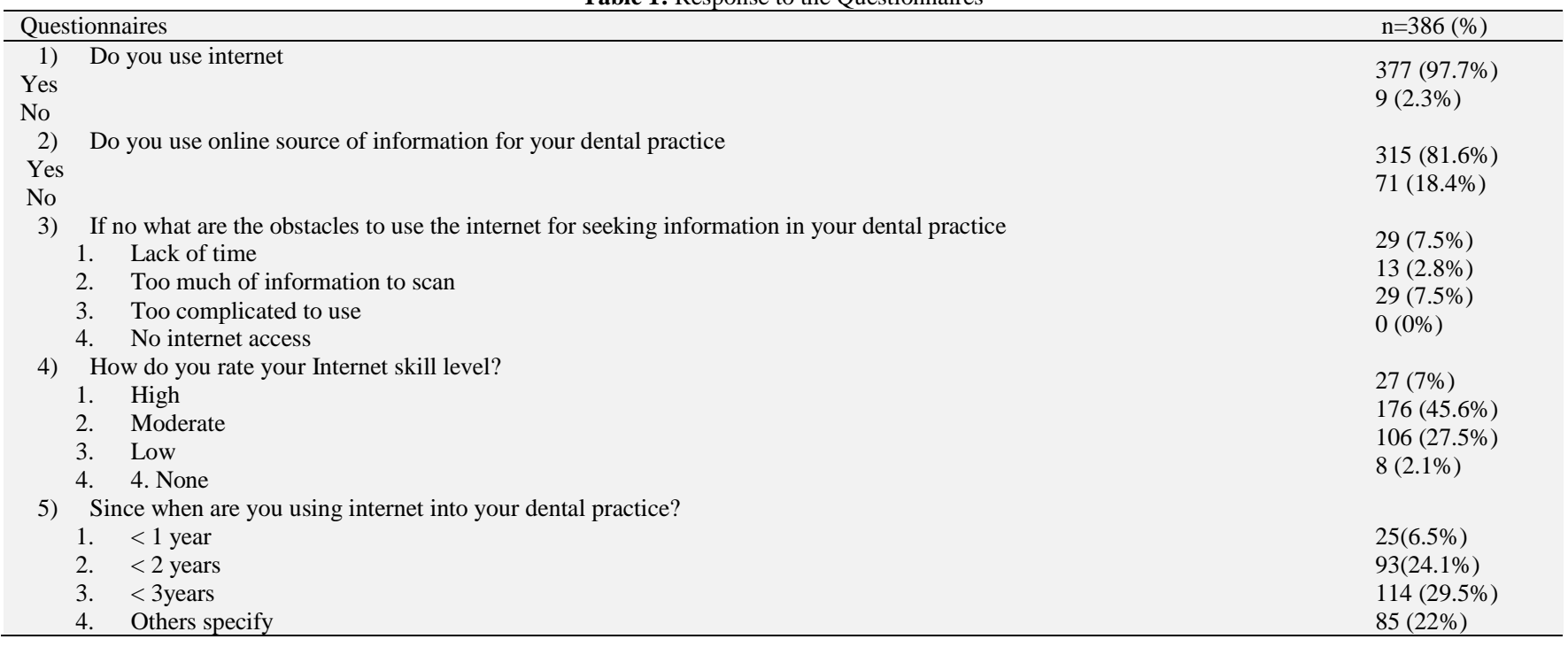

Table 2: Association of Response with Age

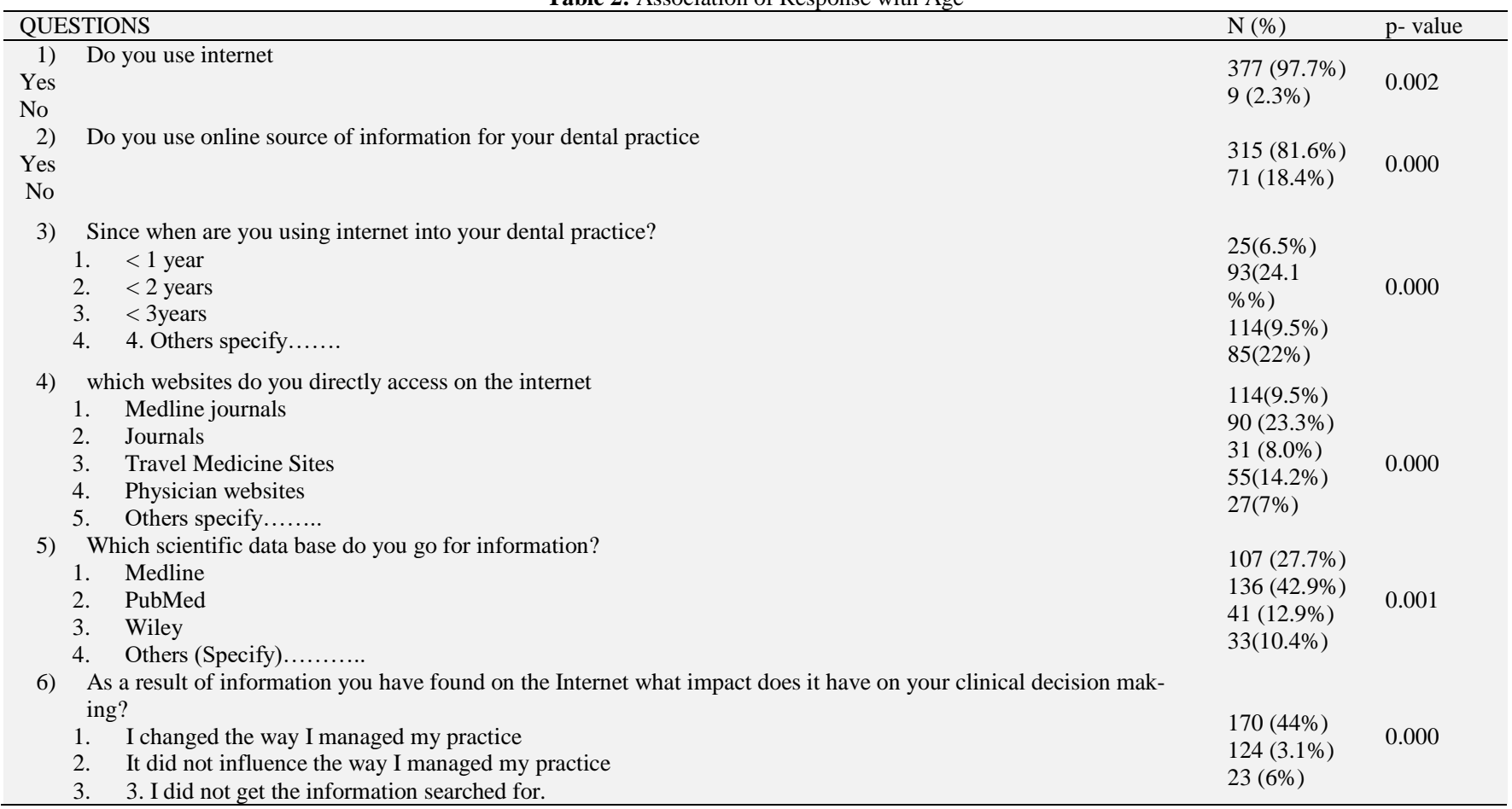


Table 3: Association of Response with Gender

\begin{tabular}{|c|c|c|c|}
\hline \multicolumn{2}{|c|}{ Questions } & $\mathrm{N}(\%)$ & p-value \\
\hline $\begin{array}{l}1) \\
\text { Yes } \\
\text { No }\end{array}$ & Do you use online source of information for your dental practice & $\begin{array}{l}315(81.6 \%) \\
71(18.4 \%)\end{array}$ & 0.004 \\
\hline 2) & $\begin{array}{l}\text { What type of dental practice related information have you searched on the Internet? } \\
\text { 1. Patient education and management } \\
\text { 2. Information related to Medical emergencies } \\
\text { 3. Information related to oral/dental disease, and its diagnosis } \\
\text { 4. Usage of latest technology into dental practice (material/ equipment/ procedure) } \\
\text { 5. Drug information }\end{array}$ & $\begin{array}{l}66(17.1 \%) \\
60(15.5 \%) \\
77(19.9 \%) \\
73(18.9 \%) \\
41(10.6 \%)\end{array}$ & 0.001 \\
\hline 3) & $\begin{array}{l}\text { Where do you get most of your Continuing Dental Education (CDE) credit points? (Please choose one) } \\
\text { 1. State / local / National dental conference } \\
\text { 2. Online CDE services } \\
\text { 3. Specialty conferences } \\
\text { 4. None }\end{array}$ & $\begin{array}{l}81(21 \%) \\
100(25.9 \%) \\
104(26.9 \%) \\
32(8.3 \%)\end{array}$ & 004 \\
\hline
\end{tabular}

Chi square test, ( $p$ value significant: $p \leq 0.05$ ).

Table 4: Association of Response with Qualification

\begin{tabular}{|c|c|c|c|}
\hline \multicolumn{2}{|c|}{ Questions } & $\mathrm{N}(\%)$ & p-value \\
\hline 1) & $\begin{array}{l}\text { Since when are you using internet into your dental practice? } \\
1 . \quad<1 \text { year } \\
2 . \quad<2 \text { years } \\
\text { 3. } \quad<\text { years } \\
\text { 4. } \quad \text { Others specify...... }\end{array}$ & $\begin{array}{l}25(6.5 \%) \\
93(24.1 \%) \\
114(29.5 \%) \\
85(22.0 \%)\end{array}$ & 0.000 \\
\hline 2) & $\begin{array}{l}\text { What type of dental practice related information have you searched on the Internet? } \\
\text { 1. Patient education and management } \\
\text { 2. Information related to Medical emergencies } \\
\text { 3. Information related to oral/dental disease, and its diagnosis } \\
\text { 4. Usage of latest technology into dental practice (material/ equipment/ procedure) } \\
\text { 5. Drug information }\end{array}$ & $\begin{array}{l}66(17.1 \%) \\
60(15.5 \%) \\
77(19.9 \%) \\
73(18.9 \%) \\
41(10.6 \%)\end{array}$ & 0.000 \\
\hline 3) & $\begin{array}{l}\text { How do you use the information you obtain from internet } \\
\text { 1. To update the information about oral disease/diagnostic procedure/treatment } \\
\text { 2. To Change or confirm treatment plan } \\
\text { 3. To Change or confirm diagnosis }\end{array}$ & $\begin{array}{l}132(33.2 \%) \\
83(22.8 \%) \\
102(26.2 \%)\end{array}$ & 0.000 \\
\hline 4) & $\begin{array}{l}\text { How do you assess the reliability and validity of medical/dental information on the internet? } \\
\text { 1. Information is published in a reputed journal } \\
\text { 2. I look at the research method used } \\
\text { 3. I look at the sources cited } \\
\text { 4. After seeking confirmation from another source }\end{array}$ & $\begin{array}{l}83(21.5 \%) \\
72(18.7 \%) \\
88(22.8 \%) \\
74(19.2 \%)\end{array}$ & 0.000 \\
\hline 5) & $\begin{array}{l}\text { which websites do you directly access on the internet } \\
\text { 1. Medline journals } \\
\text { 2. Journals } \\
\text { 3. Travel Medicine Sites } \\
\text { 4. Physician websites } \\
\text { 5. Others specify........ }\end{array}$ & $\begin{array}{l}114(29.5 \%) \\
90(23.3 \%) \\
31(8 \%) \\
55(14.2 \%) \\
27(7 \%)\end{array}$ & 0.000 \\
\hline 6) & $\begin{array}{l}\text { Which scientific data base do you go for information? } \\
\text { 1. Medline } \\
\text { 2. PubMed } \\
\text { 3. Wiley } \\
\text { 4. } \quad \text { Others (Specify)........... }\end{array}$ & $\begin{array}{l}107(27.7 \%) \\
136(42.9 \%) \\
41(12.9 \%) \\
33(10.4 \%)\end{array}$ & 0.001 \\
\hline
\end{tabular}

Chi square test, ( $p$ value significant: $p \leq 0.05$ ).

Table 5: Association of Response with Experience

\begin{tabular}{|c|c|c|c|}
\hline \multicolumn{2}{|c|}{ Questions } & \multirow[t]{2}{*}{$\mathrm{N}(\%)$} & \multirow[t]{2}{*}{ p-value } \\
\hline 1) & Do you use internet & & \\
\hline Yes & & $377(97.7 \%)$ & 0.000 \\
\hline No & & $9(2.3 \%)$ & \\
\hline 2) & Do you use online source of information for your dental practice? & & \\
\hline Yes & & $315(81.6 \%)$ & 0.000 \\
\hline No & & $71(18.4 \%)$ & \\
\hline 3) & Since when are you using internet into your dental practice? & & \\
\hline 1 & 1. $<1$ year & $25(6.5 \%)$ & \\
\hline & 2. $<2$ years & $93(24.1 \%)$ & 0.001 \\
\hline & 3. $\quad<3$ years & $114(29.5 \%)$ & \\
\hline 4 & 4. Others specify....... & $85(22 \%)$ & \\
\hline 4) & which websites do you directly access on the internet & & \\
\hline 1 & 1. Medline journals & $114(29.5 \%)$ & \\
\hline & 2. Journals & $90(23.3 \%)$ & 0.001 \\
\hline 3 & 3. Travel Medicine Sites & $31(8 \%)$ & \\
\hline
\end{tabular}


4. Physician websites

$55(14.2 \%)$

5. Others specify........

$27(7 \%)$

5) Do you believe the information in online journals is more reliable than the information published on webpages?

Yes

6) As a result of information you have found on the Internet what impact does it have on your clinical decision making?

1. I changed the way I managed my practice

3. I did not get the information searched for $23(6 \%)$

Chi square test, ( $\mathrm{p}$ value significant: $\mathrm{p} \leq 0.05$ ).

Table 6: Association of Response with Acad/Clin/Both

\begin{tabular}{|c|c|c|c|}
\hline \multicolumn{2}{|c|}{ Questions } & $\mathrm{N}(\%)$ & p-value \\
\hline \multicolumn{2}{|r|}{ 1) How do you rate your Internet skill level? } & & \multirow{5}{*}{0.001} \\
\hline & 1. High & $21(1 \%)$ & \\
\hline & 2. Moderate & $176(45.6 \%)$ & \\
\hline & 3. Low & $106(27.5 \%)$ & \\
\hline & 4. None & $8(2.1 \%)$ & \\
\hline \multirow{5}{*}{ 2) } & Since when are you using internet into your dental practice? & & \\
\hline & 1. $<1$ year & $25(6.5 \%)$ & \multirow{4}{*}{0.000} \\
\hline & 2. $<2$ years & $93(24.1 \%)$ & \\
\hline & 3. $\quad<3$ years & $114(29.5 \%)$ & \\
\hline & 4. Others specify....... & $85(22 \%)$ & \\
\hline \multirow[t]{5}{*}{ 3) } & How often do you use the Internet to obtain dental related information? & & \multirow{5}{*}{0.002} \\
\hline & 1. Frequently & $27(7 \%)$ & \\
\hline & 2. Occasionally & $176(45.6 \%)$ & \\
\hline & 3. Rarely & $99(25.6 \%)$ & \\
\hline & 4. Never & $15(3.9 \%)$ & \\
\hline \multirow[t]{5}{*}{ 4) } & What type of dental practice related information have you searched on the Internet? & $66(17.1 \%)$ & \multirow{5}{*}{0.000} \\
\hline & 2. Information related to Medical emergencies & $77(19.9 \%)$ & \\
\hline & 3. Information related to oral/dental disease, and its diagnosis & $73(18.9 \%)$ & \\
\hline & 4. Usage of latest technology into dental practice (material/ equipment/ procedure) & $41(10.6 \%)$ & \\
\hline & 5. Drug information & & \\
\hline
\end{tabular}

Chi square test, ( $p$ value significant: $p \leq 0.05$ ).

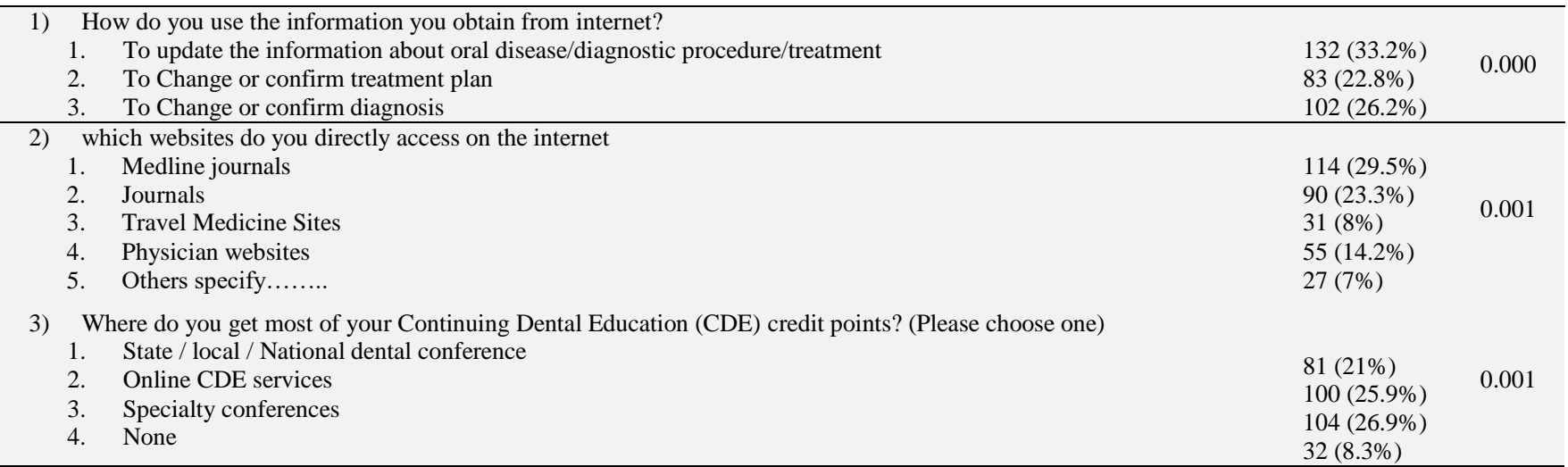

Chi square test, ( $p$ value significant: $p \leq 0.05$ ).

\section{Discussion}

Increasingly, people are more reliant on the internet to achieve a whole range of daily activities - whether it is shopping, banking, learning, staying in touch with family, socializing with friends, just taking time out to play games or listen to music, or getting help with health-related issues. Although the Internet has become an important resource for health information, little is known about key factors that affect our perceptions of how the Internet is embedded in our lives and how our lives are embedded in the Internet (Leung L 2008, P.565). There is increasing interest in evidence based dentistry (EBD) internationally and from a wide variety of dental groups (Pittis N 2004, P.2)

The Internet undoubtedly provides a fast channel for the transfer of medical information into the office of the health care professional (Michael K et al 2001, P.251). To maintain health and pre- vent dental disease effectively in this era of evidence-based healthcare and EBD we must ensure that clinical practice reflects not just findings of systematic reviews of all the relevant literature (the objective state of the science) but also the current expert and consensus views on clinical practice. (the state of the art) (Pittis N 2004, P.60)

In this study we evaluated the dentist self-reported reasons for using or not using the internet.

Hong Kong is one of the cities with the highest personal computer (PC) and internet usage in the world. In 2007, 94.5\% had connection to the internet (Yan YY 2010, P.147). in the present study 97.7\% were using the internet. Study done by Ahmann 2000, Diaz et al 2002 showed large population of people are using internet (Selvi F et al 2002, P.977)

In the present study percentage of males using internet is $54.1 \%$ and the percentage of females is $45 \%$, which is corresponding with the study done by Erik et al (Kendra L et al 2006, P.39). This 
is in contrast with the study done by (Cullen JR 2002, P.370).and (Yan YY 2010, P.147) were females are more and males are less. Study done by Romano et al shows that a large majority of the Italian pediatricians frequently use the internet during their practice, in this current study $176(45.6 \%)$ of dentist used internet occasionally (Romano M et al 2012, P.1), (Funkhouser E et al 2014, P.71), (Yan YY 2010, P.147), (Selvi F et al 2002, P.977). The majority of the clinicians accessed Medline 107 (27\%) and PubMed 136 (42\%), which is similar to the study done by (Cullen J R 2002, P.370)' and (Andrew E J 2005, P.206). Dentist were asked how they assessed the reliability and authority of medical information on the Internet relatively large number indicated that they used information published in reputed journals which is similar to the study done by (Cullen J R 2002, P.370).

Several studies have explored the use of the internet to obtain clinical information for patient's care (Ajuwon AG 2006, P.1) the majority of respondents reported that they used the internet almost every day (77\%) (John JH et al 2003, P.585). Which corresponds with the present study. In present study $73 \%$ of the dentist used internet for latest technology into dental practice. There is also an increasing body of knowledge indicating that health professionals do not regularly obtain clinically useful material from published journal articles (Pittis N 2004, P.33) which is corresponding to the present study.

Study done by Haynes and Wilczynski show that although medical literature is very accessible through online databases such as PubMed, very few clinicians are able to search them well (Cullen $\mathrm{R}$ et al, P.1) which is not corresponding to the present study.

Louis Leung study shows that those who often go to the Internet for health information and have high expectations of health information websites tend to be those who are more likely to perceive that the Internet plays an important role in life decisions. This suggests that there is a crucial link between Internet embeddedness and online health information seeking (Louis L 2008, P.565) these corresponds with the present study.

\section{Conclusion}

The internet is transforming health care, and has the potential to combine all existing health information sources. Health professionals need to be more responsive to the utilization of the internet to deliver better health care for consumers.Findings suggest, a relatively large proportion of dental practitioners use information from online sources for practice guidance, these practitioners vary with type of online use (eg: reading journals, obtaining CDE). The internet could be a valuable medium for the information. Practicing dentists feel strongly they need to keep up with new technique for patient case. Being connected to the internet would be highly advantageous to dental practices by facilitating communication with other parts of the healthcare network, enabling dentists to communicate with and promote their services to patients and giving dental practice teams access to the wide range of patient and professional resources available on-line.

\section{References}

[1] Romano Mariateresa et al. Use of the internet by Italian pediatricians: habits, impact on clinical practice and expectations. BMC Medical Informatics and Decision Making 2012; 12:23: P-1-7.

[2] R. Ni Riordain and C. McCreary. Dental patients' use of the Internet. British Dental Journal 2009; volume 207 (12) Dec 19: P-583586.

[3] J. Rowena Cullen. In search of evidence: family practitioners' use of the Internet for clinical information. J Med Libr Assoc October 2002; 90(4): P- 370-379.

[4] L. Sharon Gravois. Information seeking practices of dental hygienists. Bull Med Libr October 1995; volume 83(4): P-446- 452.

[5] Mei Song et al. How information systems should support the information needs of general dentists in clinical settings: suggestions from a qualitative study. Medical Informatics and Decision Making 2010; P-1-9.

[6] Ellen Funkhouser et al. Use of Online Sources of Information by Dental Practitioners: Findings from the Dental Practice-Based Research Network. J Public Health Dent 2014; January 74(1): P- 7179.

[7] L Kendra et al. Family Medicine Patients' Use of the Internet for Health Information: A MetroNet Study. JABFM January-February 2006; Vol. 19(1): P- 39-45.

[8] A. H Anita et al . Verhoeven. Use of information sources by family physicians: a literature survey. Bull Med Libr Assoc 1995; 83(1) : P- 85- 90 .

[9] Elizabeth Ashin Strother et al. Information Needs of Practicing Dentists. Bull. Med. Libr July 1986; 74(3): P- 227-230.

[10] N. Reem et al. Utilization of Evidence-Based Informational Resources for Clinical Decisions Related to Posterior Composite Restorations. Journal of Dental Education November 2005; Volume 69 (11): P- 1251- 1256.

[11] J. Michael Schoen et al. Characteristics That Predict Physician Participation in a WebBased CME Activity: The MI-Plus Study. J Contin Educ Health Prof 2011; 29(4): P- 246-253.

[12] Greg Ryan et al. Online CME: An effective alternative to face-toface delivery. 03 Jul 2009; P- e251-257.

[13] Louis Leung. Internet Embeddedness: Links with Online Health Information Seeking, Expectancy Value/Quality of Health Information Websites, and Internet Usage Patterns. Cyberpsychology \& Behavior 2008; Volume 11 (5): P- 565-569.

[14] Nigel Pitts. Understanding the jigsaw of evidence-based dentistry: 1 Introduction, research and synthesis. Evidence-Based Dentistry 2004; 5: P- 2-4.

[15] Koller Michael et al. Use of the Internet by medical doctors in Switzerland. Swiss Med Wkly 2001;131:P-251-254.

[16] Nigel Pitts. Understanding the jigsaw of evidence-based dentistry. 3 Implementation of research findings in clinical practice. . EvidenceBased Dentistry 2004; 5: P- 60-64.

[17] Yuk Yee Yan. Online Health Information Seeking Behavior in Hong Kong: An Exploratory Study. J Med Syst 2010; 34: P-147153

[18] Firat Selvi et al. Information-Seeking Patterns of Dentists in Istanbul, Turkey. International Section on Dental Education August 2002 ; Volume 66(8): P-977-980.

[19] E.James Andrews et al. Information-seeking behaviors of practitioners in a primary care practice-based research network (PBRN). J Med Libr Assoc April 2005; 93(2): P- 206-212.

[20] A. Grace Ajuwon et al. Use of the Internet for health information by physicians for patient

[21] Care in a teaching hospital in Ibadan, Nigeria.Biomedical Digital Libraries 2006, P-1-9.

[22] J. H. John et al. Questionnaire survey on the use of computerisation in dental practices across the Thames Valley region. British Dental Journal 2003; volume 195 (10): P- 585- 590.

[23] Nigel Pitts. Understanding the jigsaw of evidence-based dentistry. 2 Dissemination of research results. Evidence-Based Dentistry 2004; 5: P- 33-35.

[24] Rowena Cullen et al. The impact of information literacy training on clinicians entering the workforce. P-1-22.

[25] Louis Leung. Internet embeddedness: Links with Online Health information seeking, expectancy value/Quality of health information websites, and internet usage patterns. Cyberpsychology and behavior 2008;11(5): p-565-569. 